\title{
UTILIZAÇÃO DO RESÍDUO DO LEITE DE SOJA NA ELABORAÇÃO DE PAÇOCA ${ }^{1}$
}

\author{
SIN-HUEI WANG ${ }^{2}$, LAIR CHAVES CABRAL ${ }^{3}$ e GERALDO GONÇALVES BORGES ${ }^{4}$
}

\begin{abstract}
RESUMO - O presente estudo teve como objetivo utilizar resíduo do leite de soja (RLS), farinha de trigo e amendoim para formular uma paçoca de boa qualidade protéica e com boas características sensoriais. Foram misturadas 40\% de farinha de trigo torrada com 30:0 (I); 25:5 (II); 20:10 (III); 15:15 (IV); 10:20 (V) e 5:25 (VI) de farinha de amendoim torrado e decorticado, e RLS torrado, respectivamente, para o preparo de paçocas. Mediante análises químicas, foi verificado que houve uma diminuição no teor de extrato etéreo (de 19,54 a 11,51\%), porém um aumento nos teores de cinzas (de 0,99 a $1,23 \%$ ), fibra crua (de 1,56 a 5,08\%) e carboidrato (de 56,06 a 61,40\%) com o aumento das proporções do RLS. Por outro lado, o teor de proteína não foi afetado. O perfil de aminoácidos essenciais foi melhorado com o aumento das proporções do RLS nas paçocas formuladas. Resultados da avaliação sensorial indicam que as paçocas formuladas com até 15\% do RLS mostraram boas características na aparência, no sabor e na textura, sendo a de $10 \%$ do RLS a mais apreciada pela equipe massal de provadores não treinados.
\end{abstract}

Termos para indexação: soja, amendoim, formulação.

UTILIZATION OF SOYMILK RESIDUE IN PREPARING "PAÇOCA”

\begin{abstract}
The objective of the present study was to utilize the soymilk residue (SR), wheat flour and peanuts to formulate "paçoca" of good protein quality and also good sensory characteristics. The $40 \%$ of roasted wheat flour were mixed with 30:0 (I); 25:5 (II); 20:10 (III); 15:15 (IV); 10:20 (V) and 5:25 (VI) of dehulled and roasted peanut flours and SR, respectively, to prepare the above mentioned products. It was verified, with the use of chemical analyses, that the ether extract content decreased from 19.54 to $11.51 \%$, whereas the ash, fiber and carbohydrate contents increased from 0.99 to $1.23 \%$, from 1.56 to 5.08 and from 56.06 to $61.40 \%$, respectively, with an increase of the proportion of SR. On the other hand, the protein content was not affected. The essential aminoacids profile was improved with an increase of the proportion of SR. Results of sensory evaluation indicate that mixtures with up to $15 \%$ of SR showed good characteristics of appearance, flavor and texture, a mixture with $10 \%$ of SR being preferred by non-trained panelists.
\end{abstract}

Index terms: soybean, peanut, formulation.

\section{INTRODUÇÃO}

Muitos produtos têm sido desenvolvidos para atender às necessidades nutricionais, principalmente de crianças em fase escolar. A paçoca está incluída nessa

\footnotetext{
${ }^{1}$ Aceito para publicação em 23 de setembro de 1998.

${ }^{2}$ Bioq., Dr ${ }^{\mathrm{a}}$., Prof ${ }^{\mathrm{a}}$ Adjunta, Dep. Economia Doméstica-ICHSUFRRJ, CEP 23851-970 Seropédica, RJ.

${ }^{3}$ Quím., Dr., Embrapa-Centro Nacional de Pesquisa de Tecnologia Agroindustrial de Alimentos (CTAA), Av. das Américas, $n^{\circ}$ 29501, CEP 23020-470 Guaratiba, RJ. E-mail: 1cc@ctaa.embrapa.br

${ }^{4}$ Economista Doméstico.
}

categoria de alimento, dada a sua aceitabilidade geral. O amendoim é o ingrediente principal nas formulações para o seu preparo. Além dele, outros ingredientes, como fubá, açúcar, mel e gordura participam também em maiores ou menores proporções.

Conkerton \& Ory (1976) afirmaram que o sabor suave e a concentração baixa de certos fatores antinutricionais do amendoim fazem com que ele seja mais desejável como suprimento protéico, embora segundo Milner (1962), as proteínas do amendoim apresentem a metionina como aminoácido limitante primário e a treonina, a lisina e o triptofano como aminoácidos limitantes secundários. 
De acordo com Bookwalter et al. (1975), a soja contém lisina em excesso e apresenta um balanceamento satisfatório de outros aminoácidos essenciais, exceto a metionina. A mistura de soja com trigo pode melhorar a qualidade da proteína do trigo, aumentando o seu quociente de eficiência protéica (PER) (Sambucetti et al., 1976; Bressani, 1981; Gonzalez-Agramon \& Serna-Saldivar, 1988).

Considerando-se que o resíduo do leite de soja é um subproduto de pouco uso, foi utilizado este resíduo, bem como as farinhas de trigo e de amendoim para o preparo de paçoca, com o objetivo de melhorar o valor nutricional deste produto, mantendo-se suas características sensoriais agradáveis.

\section{MATERIAL E MÉTODOS}

As matérias-primas usadas neste estudo foram: farinha de trigo, amendoim e resíduo do leite de soja (RLS). Farinha de trigo e amendoim, adquiridos do comércio, e o RLS, obtido como subproduto no processamento do leite de soja, fornecido pela Embrapa-Centro Nacional de Pesquisa de Tecnologia Agroindustrial de Alimentos (CTAA), Guaratiba, RJ.

Os grãos de amendoim foram submetidos ao tratamento por microondas, o suficiente para decorticá-los. Os grãos decorticados foram, então, moídos, obtendo-se a farinha de amendoim decorticado. Já o RLS foi secado a $70^{\circ} \mathrm{C}$ por 5 horas, e logo a seguir, a $50^{\circ} \mathrm{C}$, até o peso constante.

Determinou-se, no aparelho GRANUTEST, o tamanho de partícula das farinhas de trigo e de amendoim decorticado e do RLS. Foram usados $50 \mathrm{~g}$ de cada farinha, e peneiras, cujas aberturas variaram de 20 a 200 mesh.

Realizaram-se as seguintes determinações nas farinhas de trigo e de amendoim decorticado, e no RLS: umidade, extrato etéreo, proteína bruta e cinzas, segundo a American Association of Cereal Chemists (1969), e fibra crua, de acordo com Van de Kamer \& Van Ginkel (1952).

Os grãos de amendoim (200 g) foram torrados no forno de microondas (potência média alta), durante 7 minutos. A seguir, os grãos foram decorticados e moídos, para obtenção da farinha de amendoim torrado e decorticado. A farinha de trigo ( $200 \mathrm{~g}$ ) e o RLS (200 g) foram submetidos, separadamente, à torrefação, em frigideira, por 23 e 9 minutos, respectivamente.

Foram obtidas seis diferentes formulações de paçoca, combinando-se o açúcar (22\%), a margarina $(8 \%)$ e a farinha de trigo torrada (40\%) com 30:0; $25: 5 ; 20: 10 ; 15: 15$;
10:20 e $5: 25 \%$ de farinha de amendoim torrado e decorticado, e RLS torrado, respectivamente, sendo designados como fórmulas I, II, III, IV, V e VI, respectivamente. Os ingredientes constituintes da paçoca foram homogeneizados na batedeira planetária durante $10 \mathrm{minu}$ tos e acondicionados em fôrmas com $27 \mathrm{~mm}$ de diâmetro e $13 \mathrm{~mm}$ de espessura.

Determinou-se a composição centesimal aproximada, de acordo com os métodos indicados anteriormente.

Determinaram-se aminoácidos totais, conforme o método de troca iônica de Spackman et al. (1958), e calculou-se o escore químico, segundo o método descrito pela FAO (1973).

Determinou-se a atividade do inibidor de tripsina, de acordo com o método original de Kunitz, conforme descrito por Kakade et al. (1969).

As seis paçocas formuladas foram submetidas a teste de qualidade (aparência, sabor e textura), usando-se a Escala Estruturada de nove pontos ( $1=$ extremamente ruim; $9=$ excelente). Foi usada uma equipe de dez provadores treinados, de ambos os sexos.

Selecionaram-se as amostras que apresentaram melhor aparência, sabor e textura, sendo estas submetidas à Análise Descritiva Quantitativa (QDA) dos mesmos atributos, conforme recomendações de Stone \& Sidel (1985). Uma equipe de oito provadores qualificados e treinados foi solicitada para este teste.

As amostras foram avaliadas pela QDA e submetidas a teste de preferência, usando-se a Escala Hedônica de nove pontos $(1=$ desgostei muitíssimo; $9=$ gostei muitís simo). Colaborou uma equipe de 120 provadores não treinados.

As determinações químicas foram analisadas estatisticamente por meio de análises de variância, com posterior comparação das diferenças entre as médias, pelo teste de Tukey a $5 \%$ de probabilidade. Usou-se o delineamento em blocos incompletos (DBI), com cinco repetições (plan 11.4), para testes sensoriais de qualidade (aparência, sabor e textura), com seis amostras, e com três repetições (plan 11.1) referentes aos testes de QDA, com quatro amostras. $\mathrm{O}$ delineamento de blocos casualizados (DBC) foi aplicado no teste sensorial de preferência, com quatro amostras. Todas as análises estatísticas foram realizadas segundo os métodos descritos em Pimentel-Gomes (1982) e Cochran \& Cox (1957).

\section{RESULTADOS E DISCUSSÃO}

Os resultados apresentados na Tabela 1 mostram que a farinha de trigo (FT) teve 81,94\% das partículas menores que 100 mesh, enquanto $99,45 \%$ da farinha de amendoim decorticado (FAD) ficaram 
retidos nas peneiras de 20 e 42 mesh. Já para o resíduo do leite de soja (RLS), 78,43\% foram retidos nas peneiras de 42, 60 e 80 mesh. Isto indica que a FT apresentou um tamanho de partícula menor que a FAD e o RLS, sendo a FAD a que teve partículas maiores.

Na Tabela 2, verifica-se que o RLS apresentou teor de fibra crua $(18,18 \%)$ superior aos teores da FT e da FAD. A FAD destacou-se pelos seus elevados conteúdos de proteínas $(35,81 \%)$ e extrato etéreo $(47,93 \%)$, mas o RLS também mostrou tais teores. A FT se sobressaiu pelo alto teor de carboidrato $(84,31 \%)$.

A Tabela 3 ilustra a composição centesimal aproximada (\% base úmida) das paçocas elaboradas à base de farinha de trigo, amendoim e RLS em diferentes proporções. Os dados mostram que ocorreu uma diminuição no teor de extrato etéreo (de 19,54 a $11,51 \%$ ) com o aumento das proporções do RLS nas paçocas formuladas. Por outro lado, os teores de cinzas (de 0,99 a 1,23\%), fibra crua (de 1,56 a $5,08 \%$ ) e carboidrato (de 56,06 a 61,40\%) aumentaram com a elevação das proporções do RLS, enquanto o de proteína não foi afetado. Sem dúvida, o RLS apresentou teor de extrato etéreo mais baixo, porém contém teores mais altos de cinzas, fibra crua e carboidrato do que os de amendoim, o que explica o resultado encontrado.

A Tabela 4 apresenta a composição em aminoácidos e a Tabela 5 indica os escores de aminoácidos essenciais das paçocas elaboradas à base de farinha de trigo, amendoim e RLS, em diferentes proporções. Através dessas tabelas, verifica-se que o aumento das proporções do RLS resultou um aumento nos teores de aminoácidos essenciais. Já os aminoácidos não-essenciais diminuíram com o aumento das proporções do RLS. Escores de lisina, treonina e aminoácidos sulfurados

TABELA 1. Distribuição do tamanho de partícula de farinhas de trigo e de amendoim decorticado, e do resíduo do leite de soja.

\begin{tabular}{ccccc}
\hline $\begin{array}{c}\text { Mesh } \\
\text { (tyler })\end{array}$ & $\begin{array}{c}\text { Abertura da malha } \\
(\mathrm{mm})\end{array}$ & $\begin{array}{c}\text { Farinha de trigo } \\
(\%)\end{array}$ & $\begin{array}{c}\text { Farinha de amendoim } \\
\text { decorticado }(\%)\end{array}$ & $\begin{array}{c}\text { Resíduo do leite de soja } \\
(\%)\end{array}$ \\
\hline 20 & 0,84 & 0 & 64,97 & 0,07 \\
42 & 0,35 & 0 & 34,48 & 44,43 \\
60 & 0,25 & 0,86 & 0,55 & 23,70 \\
80 & 0,177 & 8,19 & 0 & 10,30 \\
100 & 0,149 & 9,01 & 0 & 7,16 \\
150 & 0,105 & 17,16 & 0 & 10,17 \\
200 & 0,074 & 24,82 & 0 & 3,20 \\
Fundo $<200$ & $<0,074$ & 39,96 & 0 & 0,97 \\
\hline
\end{tabular}

TABELA 2. Composição centesimal aproximada (\% base seca) de farinhas de trigo e de amendoim decorticado, e do resíduo do leite de soja ${ }^{1}$.

\begin{tabular}{lccccc}
\hline Composição & $\begin{array}{c}\text { Farinha de } \\
\text { trigo }\end{array}$ & $\begin{array}{c}\text { Farinha de } \\
\text { amendoim } \\
\text { decorticado }\end{array}$ & $\begin{array}{c}\text { Resíduo do leite } \\
\text { de soja }\end{array}$ & D.M.S & $\begin{array}{c}\text { C.V. } \\
(\%)\end{array}$ \\
\hline Proteína (\%) & $13,40 \mathrm{C}$ & $35,81 \mathrm{~A}$ & $31,69 \mathrm{~B}$ & 0,30 & 0,26 \\
Extrato etéreo (\%) & $1,42 \mathrm{C}$ & $47,93 \mathrm{~A}$ & $15,37 \mathrm{~B}$ & 3,81 & 4,23 \\
Cinzas $(\%)$ & $0,70 \mathrm{C}$ & $2,02 \mathrm{~B}$ & $3,25 \mathrm{~A}$ & 0,10 & 1,18 \\
Fibra crua (\%) & $0,17 \mathrm{C}$ & $3,97 \mathrm{~B}$ & $18,18 \mathrm{~A}$ & 0,17 & 0,55 \\
Carboidrato $^{2}(\%)$ & $84,31 \mathrm{~A}$ & $10,27 \mathrm{C}$ & $31,51 \mathrm{~B}$ & 3,70 & 2,11 \\
\hline
\end{tabular}

${ }^{1}$ As médias seguidas de letra diferente diferem estatisticamente entre si pelo teste de Tukey a $5 \%$ de probabilidade.

${ }^{2}$ Calculado por diferença. 
TABELA 3. Composição centesimal aproximada (\% base úmida) das paçocas elaboradas à base de farinha de trigo, amendoim e resíduo do leite de soja (RLS) em diferentes proporções ${ }^{1}$.

\begin{tabular}{|c|c|c|c|c|c|c|}
\hline Fórmula ${ }^{2}$ & $\begin{array}{l}\text { Umidade } \\
(\%)\end{array}$ & $\begin{array}{c}\text { Proteína } \\
(\%)\end{array}$ & $\begin{array}{c}\text { Extrato etéreo } \\
(\%)\end{array}$ & $\begin{array}{c}\text { Cinzas } \\
(\%)\end{array}$ & $\begin{array}{c}\text { Fibra crua } \\
(\%)\end{array}$ & $\begin{array}{c}\text { Carboidrato }^{3} \\
(\%)\end{array}$ \\
\hline I & $6,63 a$ & 15,22 & $19,54 \mathrm{a}$ & $0,99 \mathrm{~b}$ & $1,56 \mathrm{f}$ & $56,06 \mathrm{c}$ \\
\hline II & $6,30 \mathrm{ab}$ & 15,13 & $17,17 \mathrm{~b}$ & $1,02 b$ & $2,18 \mathrm{e}$ & $58,20 \mathrm{~b}$ \\
\hline III & $6,16 b$ & 15,11 & $15,00 \mathrm{c}$ & $1,16 \mathrm{a}$ & $3,02 \mathrm{~d}$ & $59,55 b$ \\
\hline IV & $6,05 \mathrm{~b}$ & 14,80 & $13,29 \mathrm{~d}$ & $1,16 \mathrm{a}$ & $3,65 \mathrm{c}$ & $61,05 a$ \\
\hline $\mathrm{V}$ & $6,02 \mathrm{~b}$ & 14,89 & $12,39 \mathrm{e}$ & $1,16 \mathrm{a}$ & $4,39 b$ & $61,15 \mathrm{a}$ \\
\hline VI & $6,02 \mathrm{~b}$ & 14,76 & $11,51 \mathrm{f}$ & $1,23 \mathrm{a}$ & $5,08 \mathrm{a}$ & $61,40 \mathrm{a}$ \\
\hline D.M.S. & 0,46 & - & 0,72 & 0,13 & 0,37 & 1,36 \\
\hline C.V. (\%) & 2,69 & 1,69 & 1,78 & 4,37 & 4,13 & 0,83 \\
\hline
\end{tabular}

1 As médias seguidas de letra diferente diferem estatisticamente entre si pelo teste de Tukey a 5\% de probabilidade.

${ }^{2}$ Fórmula I: 0\% RLS; Fórmula II: 5\% RLS; Fórmula III: 10\% RLS; Fórmula IV: 15\% RLS; Fórmula V: 20\% RLS; Fórmula VI: $25 \%$ RLS.

3 Calculado por diferença.

TABELA 4. Composição em aminoácidos (g/16 g N) das paçocas elaboradas à base de farinha de trigo, amendoim e resíduo do leite de soja (RLS) em diferentes proporções ${ }^{1}$.

\begin{tabular}{|c|c|c|c|c|c|c|}
\hline \multirow[t]{2}{*}{ Aminoácidos } & \multicolumn{6}{|c|}{ Paçocas formuladas } \\
\hline & $\mathrm{I}$ & II & III & IV & $\mathrm{V}$ & VI \\
\hline Ác. aspártico & 14,48 & 13,60 & 11,14 & 9,84 & 9,22 & 9,31 \\
\hline Treonina & 2,87 & 2,87 & 2,90 & 2,98 & 3,27 & 4,35 \\
\hline Serina & 6,02 & 5,58 & 4,71 & 4,54 & 4,47 & 4,33 \\
\hline Ác. glutâmico & 25,60 & 22,83 & 21,96 & 19,89 & 19,75 & 19,68 \\
\hline Prolina & 4,42 & 2,59 & 2,28 & 1,31 & 1,30 & 1,16 \\
\hline Glicina & 5,30 & 5,12 & 4,78 & 4,11 & 3,70 & 3,59 \\
\hline Alanina & 4,46 & 4,45 & 3,56 & 3,50 & 3,33 & 3,26 \\
\hline 1/2 Cistina & 1,69 & 1,94 & 2,08 & 2,25 & 2,32 & 2,29 \\
\hline Valina & 3,69 & 3,72 & 3,96 & 4,06 & 4,69 & 4,73 \\
\hline Metionina & 0,31 & 0,43 & 0,50 & 0,53 & 0,63 & 0,69 \\
\hline Isoleucina & 3,04 & 3,10 & 3,40 & 3,96 & 4,02 & 4,40 \\
\hline Leucina & 6,10 & 6,19 & 6,61 & 7,58 & 7,95 & 8,24 \\
\hline Tirosina & 1,56 & 1,74 & 1,76 & 2,09 & 2,12 & 2,30 \\
\hline Fenilalanina & 3,83 & 3,92 & 4,10 & 4,19 & 4,24 & 4,57 \\
\hline Histidina & 3,47 & 3,28 & 2,92 & 2,68 & 2,34 & 2,38 \\
\hline Lisina & 2,79 & 3,30 & 3,85 & 4,35 & 5,02 & 5,42 \\
\hline Arginina & 11,15 & 9,64 & 7,11 & 7,03 & 6,08 & 5,84 \\
\hline
\end{tabular}

TABELA 5. Escores de aminoácidos essenciais (\%) das paçocas elaboradas à base de farinha de trigo, amendoim e resíduo do leite de soja (RLS) em diferentes proporções ${ }^{1}$.

\begin{tabular}{|c|c|c|c|c|c|c|}
\hline \multirow[t]{2}{*}{ Aminoácidos } & \multicolumn{6}{|c|}{ Paçocas formuladas } \\
\hline & I & II & III & IV & $\mathrm{V}$ & VI \\
\hline Isoleucina & 76 & 78 & 85 & 99 & 101 & 110 \\
\hline Leucina & 87 & 88 & 94 & 108 & 114 & 118 \\
\hline Lisina & 51 & 60 & 70 & 79 & 91 & 99 \\
\hline Metionina + cistina & 57 & 68 & 74 & 79 & 84 & 85 \\
\hline Fenilalanina + tirosina & 90 & 94 & 98 & 105 & 106 & 115 \\
\hline Treonina & 72 & 72 & 73 & 75 & 82 & 109 \\
\hline Triptofano & 一 & - & - & - & - & - \\
\hline Valina & 74 & 74 & 79 & 81 & 94 & 95 \\
\hline
\end{tabular}

1 Fórmula I: 0\% RLS; Fórmula II: 5\% RLS; Fórmula III: 10\% RLS; Fórmula IV: 15\% RLS; Fórmula V: 20\% RLS; Fórmula VI: 25\% RLS. 
que são limitantes em amendoim, conforme Milner (1962), foram melhorados à medida que aumentava a proporção do RLS, embora o aumento em aminoácidos sulfurados não tenha sido tão relevante. Os perfis de aminoácidos essenciais foram melhorados nas paçocas formuladas com proporções acima de 5\% do RLS. Resultado semelhante foi verificado por Bookwalter et al. (1979), os quais constataram que os níveis de lisina e treonina são muito mais altos na proteína de soja do que na de amendoim, o que contribui para o valor mais alto de quociente da eficiência protéica (PER) da mistura de milhosoja do que o de milho-amendoim.

Não houve nenhuma atividade residual do inibidor de tripsina nas paçocas formuladas estudadas, o que mostra que a torrefação da farinha de trigo, amendoim e RLS usada na formulação de paçoca foi suficiente para inativar completamente o inibidor de tripsina.

No estudo e desenvolvimento de novos produtos alimentícios, as propriedades organolépticas devem ser consideradas como fator de suma importância na sua aceitabilidade por parte dos consumidores.

A Tabela 6 mostra os resultados de escores de avaliação sensorial de aparência, sabor e textura relativos às paçocas elaboradas à base de farinha de trigo, amendoim e RLS em diferentes proporções. Observa-se que todas as paçocas formuladas contendo (de 5 a $25 \%$ ), ou não, o RLS, obtiveram escores de

TABELA 6. Escores de avaliação sensorial de aparência, sabor e textura das paçocas elaboradas à base de farinha de trigo, amendoim e resíduo do leite de soja (RLS), em diferentes proporções ${ }^{1}$.

\begin{tabular}{cccc}
\hline Fórmula $^{2}$ & Aparência & Sabor & Textura \\
\hline I & $7,88 \mathrm{~b}$ & $8,60 \mathrm{a}$ & $8,10 \mathrm{a}$ \\
II & $8,08 \mathrm{ab}$ & $8,04 \mathrm{~b}$ & $8,04 \mathrm{a}$ \\
III & $8,12 \mathrm{a}$ & $8,02 \mathrm{~b}$ & $8,02 \mathrm{a}$ \\
IV & $8,08 \mathrm{ab}$ & $7,54 \mathrm{c}$ & $7,64 \mathrm{~b}$ \\
V & $7,96 \mathrm{ab}$ & $7,04 \mathrm{~d}$ & $6,86 \mathrm{c}$ \\
VI & $7,92 \mathrm{ab}$ & $6,66 \mathrm{e}$ & $6,10 \mathrm{~d}$ \\
\hline D.M.S. & 0,22 & 0,18 & 0,18 \\
C.V. $(\%)$ & 1,32 & 1,13 & 1,21 \\
\hline
\end{tabular}

1 As médias seguidas de letra diferente diferem estatisticamente entre si pelo teste de Tukey a 5\% de probabilidade.

2 Fórmula I: 0\% RLS; Fórmula II: 5\% RLS; Fórmula III: 10\% RLS; Fórmula IV: 15\% RLS; Fórmula V: 20\% RLS; Fórmula VI: 25\% RLS. aparência semelhantes, sendo a paçoca formulada III, contendo $10 \%$ do RLS, a que mostrou aparência superior, e a paçoca formulada I, não contendo o RLS, aparência inferior. As paçocas formuladas II e III, com 5 e $10 \%$ do RLS, respectivamente, apresentaram escores de sabor menores do que a paçoca formulada sem RLS, não havendo diferença significativa entre si, embora com escores superiores às demais paçocas formuladas (de 15 a $25 \%$ do RLS). A adição de até $10 \%$ do RLS nas paçocas não causou a modificação de sua textura, sendo iguais às paçocas formuladas sem e com 5\% do RLS. Por outro lado, as formulações contendo mais que $10 \%$ do RLS mostraram perdas significativas nos escores de sabor e textura, embora a paçoca formulada IV com $15 \%$ do RLS apresentasse sabor e textura agradáveis $(7,54$ e 7,64, respectivamente, sendo $7=$ bom). Desta forma, foram usadas apenas paçocas formuladas com até $15 \%$ do RLS para serem submetidas à Análise Descritiva Quantitativa (QDA), bem como ao teste de preferência.

Na Tabela 7 estão mostrados os resultados da QDA referente a sabor (incluindo sabor residual) e textura de paçocas elaboradas à base de farinha de trigo, amendoim e RLS em diferentes proporções. Os resultados indicam que, com o aumento das proporções do RLS (de 0 a 15\%) nas paçocas formuladas, os sabores adstringente e de soja foram percebidos com maior intensidade, enquanto os sabores de amido, trigo, amendoim, doce, gordura e torrado diminuíram. Por outro lado, os sabores amargo e cru (de erva) não foram significativamente afetados. Os sabores residuais amargo, adstringente e de soja aumentaram, enquanto o de amendoim diminuiu com o aumento das proporções do RLS. Gomosidade e adesividade foram crescentes com o aumento das proporções do RLS (de 0 a 15\%), enquanto foi verificado o contrário para a mastigabilidade. Não houve diferença significativa entre as paçocas formuladas em estudo quanto a dureza, fraturabilidade e recobrimento na boca.

Por meio da Tabela 8 , verifica-se que a paçoca formulada III, com $10 \%$ do RLS, obteve os escores superiores às demais paçocas formuladas, sendo a mais apreciada pela equipe massal de provadores. Com exceção desta, a preferência pela paçoca diminuiu com o aumento das proporções do RLS. 
TABELA 7. Escores da análise descritiva quantitativa (QDA) para atributos sensoriais de paçocas elaboradas à base de farinha de trigo, amendoim e resíduo do leite de soja (RLS) em diferentes proporções ${ }^{1}$.

\begin{tabular}{|c|c|c|c|c|c|c|}
\hline \multirow{2}{*}{$\begin{array}{l}\text { Atributos } \\
\text { sensoriais }\end{array}$} & \multicolumn{4}{|c|}{ Fórmula $^{2}$} & \multirow[t]{2}{*}{ D.M.S. } & \multirow{2}{*}{$\begin{array}{l}\text { C.V. } \\
(\%)\end{array}$} \\
\hline & I & II & III & IV & & \\
\hline \multicolumn{7}{|l|}{ Sabor } \\
\hline Amido & $1,46 \mathrm{~A}$ & $1,44 \mathrm{~B}$ & $1,44 \mathrm{~B}$ & $1,39 \mathrm{C}$ & 0,02 & 0,45 \\
\hline Trigo & $2,60 \mathrm{~A}$ & $1,92 \mathrm{~B}$ & $1,89 \mathrm{C}$ & $1,89 \mathrm{C}$ & 0,03 & 0,42 \\
\hline Amendoim & $3,49 \mathrm{~A}$ & $2,88 \mathrm{~B}$ & $2,17 \mathrm{C}$ & $2,15 \mathrm{C}$ & 0,04 & 0,39 \\
\hline Soja & $0,81 \mathrm{C}$ & $0,83 \mathrm{C}$ & $1,33 \mathrm{~B}$ & $1,39 \mathrm{~A}$ & 0,03 & 0,70 \\
\hline Doce & $2,48 \mathrm{~A}$ & $2,15 \mathrm{~B}$ & $2,07 \mathrm{C}$ & $2,02 \mathrm{C}$ & 0,06 & 0,66 \\
\hline Gordura & $0,79 \mathrm{~A}$ & $0,66 \mathrm{~B}$ & $0,66 \mathrm{~B}$ & $0,63 \mathrm{~B}$ & 0,04 & 1,51 \\
\hline Amargo & 0,24 & 0,24 & 0,25 & 0,26 & - & 2,34 \\
\hline Adstringente & $0,97 \mathrm{D}$ & $1,10 \mathrm{C}$ & $1,15 \mathrm{~B}$ & $1,53 \mathrm{~A}$ & 0,03 & 0,64 \\
\hline Torrado & $2,06 \mathrm{~A}$ & $1,95 \mathrm{~B}$ & $1,93 \mathrm{~B}$ & $1,25 \mathrm{C}$ & 0,02 & 0,36 \\
\hline Cru (de erva) & 0,52 & 0,52 & 0,53 & 0,54 & - & 2,11 \\
\hline \multicolumn{7}{|l|}{ Residual } \\
\hline Amargo & $0,20 \mathrm{~B}$ & $0,20 \mathrm{~B}$ & $0,22 \mathrm{~A}$ & $0,23 \mathrm{~A}$ & 0,01 & 1,34 \\
\hline Adstringente & $0,92 \mathrm{~B}$ & $0,92 \mathrm{~B}$ & $1,18 \mathrm{~A}$ & $1,19 \mathrm{~A}$ & 0,05 & 1,20 \\
\hline Amendoim & $3,35 \mathrm{~A}$ & $2,35 \mathrm{~B}$ & $1,89 \mathrm{C}$ & $1,86 \mathrm{D}$ & 0,02 & 0,21 \\
\hline Soja & $0,61 \mathrm{D}$ & $0,65 \mathrm{C}$ & $0,93 \mathrm{~B}$ & $0,99 \mathrm{~A}$ & 0,02 & 0,81 \\
\hline \multicolumn{7}{|l|}{ Textura } \\
\hline Dureza & 0,79 & 0,68 & 0,65 & 0,61 & - & 18,73 \\
\hline Fraturabilidade & 1,02 & 0,88 & 0,77 & 0,77 & - & 26,20 \\
\hline Mastigabilidade & $1,22 \mathrm{~A}$ & $1,19 \mathrm{AB}$ & $1,17 \mathrm{~B}$ & $1,04 \mathrm{C}$ & 0,04 & 0,86 \\
\hline Gomosidade & $2,53 \mathrm{D}$ & $2,64 \mathrm{C}$ & $2,69 \mathrm{~B}$ & $2,75 \mathrm{~A}$ & 0,01 & 0,11 \\
\hline Adesividade & $2,69 \mathrm{C}$ & $2,98 \mathrm{~B}$ & $3,06 \mathrm{~A}$ & $3,07 \mathrm{~A}$ & 0,02 & 0,14 \\
\hline Recobrimento na boca & 2,00 & 2,05 & 2,21 & 2,34 & - & 14,80 \\
\hline
\end{tabular}

TABELA 8. Preferência de paçocas elaboradas à base de farinha de trigo, amendoim e resíduo do leite de soja (RLS), em diferentes proporções ${ }^{1}$.

\begin{tabular}{cc}
\hline Fórmula $^{2}$ & Preferência \\
\hline I & $8,60 \mathrm{~b}$ \\
II & $8,04 \mathrm{c}$ \\
III & $8,98 \mathrm{a}$ \\
IV & $7,06 \mathrm{~d}$ \\
\hline D.M.S. & 0,15 \\
C.V. $(\%)$ & 1,63 \\
\hline
\end{tabular}

1 As médias seguidas de letra diferente diferem estatisticamente entre si pelo teste de Tukey a $5 \%$ de probabilidade.

2 Fórmula I: 0\% RLS; Fórmula II: 5\% RLS; Fórmula III: 10\% RLS Fórmula IV: 15\% RLS; Fórmula V: 20\% RLS; Fórmula VI: 25\% RLS.

\section{CONCLUSÕES}

1. O aumento das proporções do resíduo do leite de soja (RLS) na formulação de paçoca contendo $40 \%$ de farinha de trigo, resulta numa diminuição no teor de extrato etéreo e num aumento nos teores de cinzas, fibra crua e carboidrato, porém não é afetado o teor de proteína.

2. A melhoria dos perfis de aminoácidos essenciais das paçocas formuladas é observada desde que haja 5\% de substituição de amendoim pelo RLS.

3. As paçocas formuladas com farinha de trigo:amendoim:RLS nas proporções de 40:25:5 e 40:20:10, respectivamente, não se diferenciam entre si na aparência, no sabor e na textura, e mos- 
tram aparência superior, textura igual, e sabor inferior ao da paçoca formulada sem RLS; a paçoca formulada com $10 \%$ do RLS é a mais apreciada pela equipe massal de provadores.

\section{REFERÊNCIAS}

AMERICAN ASSOCIATION OF CEREAL CHEMISTS. Approved methods of the American Association of Cereal Chemists. 7.ed. St. Paul, 1969. $2 \mathrm{v}$

BOOKWALTER, G.N.; ANDERSON, R.A.; MUSTAKAS, G.C.; GRIFFIN JUNIOR, E.L. Fortification of dry soybean-based foods with DLmethionine. Journal of Food Science, Chicago, v.40, n.2, p.266-272, 1975 .

BOOKWALTER, G.N.; WARNER, K.; ANDERSON, R.A.; BAGLEY, E.B. Peanut-fortified food blends. Journal of Food Science, Chicago, v.44, n.6, p.820825, 1979.

BRESSANI, R. The role of soybeans in food systems. Journal of the American Oil Chemists Society, Chicago, v.58, n.3, p.392-399, 1981.

COCHRAN, W.G.; COX, G.M. Experimental Designs. 2.ed. NewYork: John Wiley, 1957. 611p.

CONKERTON, E.J.;ORY, R.L. Peanut proteins as food supplements; a compositional study of selected Virginia and Spanish peanuts. Journal of the American Oil Chemists Society, Chicago, v.53, n.12, p.754-756, 1976.

FAO (Roma, Itália). Energy and protein requirements; report of a joint FAO/WHO. Geneva: WHO, 1973. p.62-64. (WHO technical report series, 522; FAO Nutrition Meetings report series, 52).
GONZALEZ-AGRAMON, M.; SERNA-SALDIVAR, S.O. Effect of defatted soybean and soybean isolate fortification on the nutritional, physical, chemical and sensory properties of wheat flour tortillas. Journal of Food Science, Chicago, v.53, n.3, p.793-797, 1988.

KAKADE, M.L.; SIMONS, N.R.; LIENER, I.E. An evaluation of natural vs. synthetic substrates for measuring the antitrytic activity of soybean samples. Cereal Chemistry, St. Paul, v.46, n.5, p.518-526, 1969.

MILNER, M. Peanuts as protein resource in international feed programs. Food Technology, Chicago, v.16, n.7, p.46-53, 1962.

PIMENTEL-GOMES, F. Curso de Estatística Experimental. 10.ed. São Paulo: Nobel, 1982. 430p.

SAMBUCETTI, M.E.; SCICLI, G.G.; SANAHUJA, J.C. Enriquecimiento de la harina de trigo con harinas de soya y girasol para la obtención de productos de panadería. Archivos Latinoamericanos de Nutrición, Caracas, v.26, n.3, p.353-364, 1976.

SPACKMAN, D.C.; STEIN, W.H.; MOORE, S. Automatic recording apparatus for use in the chromatography of amino acids. Analytical Chemistry, Easton, v.30, n.7, p.1190-1206, 1958.

STONE, H.; SIDEL, J.L. Sensory evaluation practices. Orlando: Academic, 1985.311p.

VAN DE KAMER, J.H.; VAN GINKEL, L. Rapid determination of crude fiber in cereals. Cereal Chemistry, St. Paul, v.29, n.4, p.239-251, 1952. 